\title{
The Proposal of Key Performance Indicators in Facility Management and Determination the Weights of Significance
}

\author{
Jarmila Rimbalová, Silvia Vilčeková \\ Technical University of Košice \\ Civil Engineering Faculty, Institute of Environmental Engineering, Department of Environmental Engineering \\ e-mail: jarmila.rimbalova@tuke.sk, silvia.vilcekova@tuke.sk
}

\begin{abstract}
The practice of facilities management is rapidly evolving with the increasing interest in the discourse of sustainable development. The industry and its market are forecasted to develop to include non-core functions, activities traditionally not associated with this profession, but which are increasingly being addressed by facilities managers. The scale of growth in the built environment and the consequential growth of the facility management sector is anticipated to be enormous. Key Performance Indicators (KPI) are measure that provides essential information about performance of facility services delivery. In selecting KPI, it is critical to limit them to those factors that are essential to the organization reaching its goals. It is also important to keep the number of KPI small just to keep everyone's attention focused on achieving the same KPIs. This paper deals with the determination of weights of KPI of FM in terms of the design and use of sustainable buildings.
\end{abstract}

Key words: facility management, key performance indicators, sustainable buildings

\section{Introduction}

Facility management (FM) is a dynamic field that relates to the general public. Today's FM must cope with financial crisis, which has a significant impact on the client, especially in terms of price reduction. Clients are not willing to lose sight of the quality of services and there facility manager starts work by manage the building, on the one hand, the client is satisfied, on the other hand, the instructions for operating personnel and third-party employer who needs to reduce costs to a minimum. The most important component of facility manager work is the communication skills at all these three levels. If the company is not able to offer one in the lower price is that the manager was able to make an offer to the client or another service, which subsequently gets into a state of satisfaction. It is a manager, who applies these offered services of the facility management more effectively. It is very important to do a proper design of the measurement methods for monitoring of the processes concerned in the provision of facility management services. That's why key performance indicators (KPI) are 
introduce, which express the essential information about the performance of service delivery facility management. In general, the application of the KPI evaluation of staff acts as an incentive, if workers are able to influence KPI indicators by their behavior as well as they are regularly informed about its value. The crucial factors in determining the relevant KPI is the analyzing the impact of the related processes, the possibility of collecting the data necessary to quantify the pointer and the active involvement of internal staff.

\section{Facility Management and Sustainability}

Sustainability is an important topic for facility management professionals, and is becoming more of a mandatory practice than an optional trend. Many global, financial and environmental factors are contributing to the need for a shift to sustainability. Facility management can add substantially to the sustainability of an organization because it covers a broad spectrum of activities concerning economic, environmental and social aspects. Facility management with its holistic approach will play an important role in the next years to manage the future requirements [1] as is showed in Fig. 1.

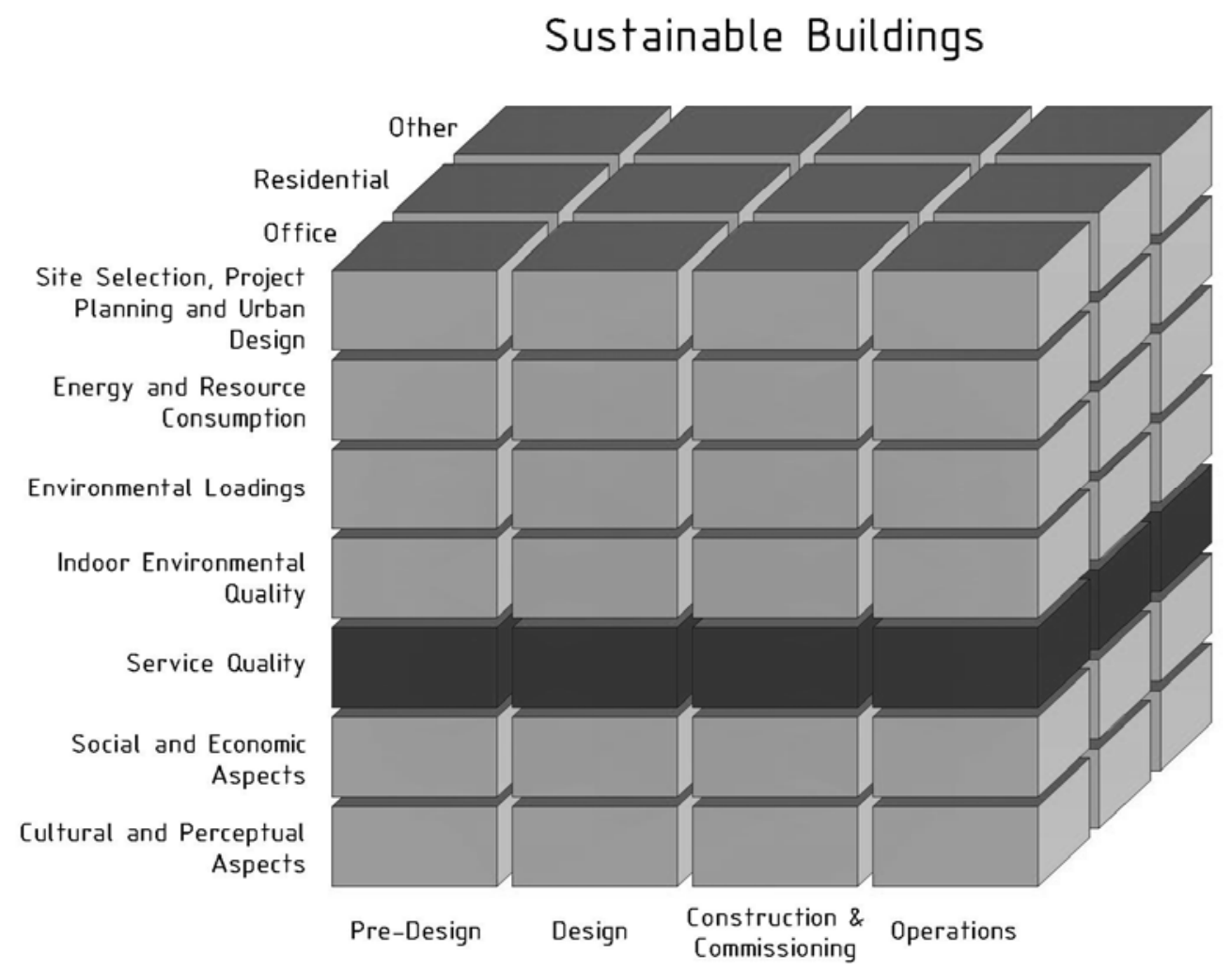

Figure 1: Wide range of options for sustainable development with reference to service quality - facility management [2]

Thinking and acting sustainable is simply a necessity nowadays. Ecological, economic and social aspects must be taken into account that in what we do - from designing the office for use of the building. Sustainable development is development that meets the needs of the 
present without compromising the ability of future generations to meet their own needs. At the same time, according to [3] it is more correct and consistent definition made, which says: sustainable company, product or process is one that can be permanent or may be produced also in the long term without having an adverse effect on the conditions necessary to promote equal activities in the future. Sustainability addressing in the civil engineering includes an assessment of the three basic dimensions of sustainability - economic, environmental and social [3]. These three dimensions form an integrated design for sustainability by their joinder.

Civil engineering is the largest consumer of resources and a large producer of waste and harmful emissions. It has a decisive influence on the whole environmental system and hence the effectiveness's of all environmental measures targeted at ensuring sustainable development. Optimizing the design, implementation and operation of buildings in terms of the criteria of sustainable development becomes an important element of facility management.

\section{Characteristics of Key Performance Indicators}

According to [4] the key performance indicators are defined as indicators showing the relevant information about the performance of service facility management supply. The overall performance of the company is composed of the performance of each of its parts, it is very important to proper distribution of selected indicators to specific processes, so-called KPI disaggregating. Well-chosen KPIs allow sufficient accuracy to monitor the performance of a particular process in order to produce output and value added.

United Kingdom, as mentioned above, has a long history in the use of key performance indicators. According to a study [5] the key performance indicators of facility management are divided into the following three main groups:

- economic (client satisfaction - product, client satisfaction - service, profitability, cost predictability (project, design, construction), time predictability (project, design, construction), productivity, safety, defects, cost and time);

- social (employee satisfaction, staff turnover, sick absence, safety, working hours, qualifications and skills, equality and diversity, training, pay and investors in people);

- environmental (impact on the environment - product and construction process, energy use (design) - product, energy use - construction process, mains water use (design) product, mains water use - construction process, waste - construction process, commercial vehicle movement - construction processes, impact on biodiversity product and construction process, area of habitat created/retained - product and whole life performance - product.

According to another study [6], the facility management evaluated in terms of five aspects: security, cleaning, repairs and maintenance, landscape and leisure, and general management, by the questionnaire survey. The focus group participants were requested to provide sample questionnaires used by their companies for soliciting residential users' responses on their satisfaction with FM services. Tools for assessing performance of FM services are the leading Post-Occupancy Evaluation (POE) tools for measuring building performance, according to [7], include the Building Quality Assessment (BQA) in New Zealand, the Serviceability Tools and Methods (STM) in Canada, and the Post-occupancy Review Of Buildings and their 
Engineering (PROBE) in the UK. In the US, a web-based occupant survey has been developed for quantifying building performance, which focuses on employee's satisfaction with their workplace environment. Given the increasing significance of FM services for the buildings, studies in this area have grown. According to [8] to monitor and measure the quality of service by the following five aspects: physical assets, reliability, response, security and empathy, which are then divided into a number of monitored subgroup. These are then evaluated and established for them scales significance. In another study [9] has developed a system for assessing the health and safety of residential homes. The above studies all share a common focus, which is on assessing the quality of the delivered service. Studies investigating also the amount of input resources, which affects the service quality, are yet to be seen. As experienced in a prior study [10], collection of empirical cost data of FM services for existing buildings is really difficult. Without a proper evaluation of the effectiveness of such input resources, assessing solely the outcome performance of FM services would render the evaluation to remain partial. It is very important to properly design the measurement methods for monitoring of the processes concerned in the provision of facility management services. It is essential to design cohesive and coherent data management systems to a trusted format in order to ensure that the system performance is monitored properly, that reliability data is collected and that the relevant people are trained to analyze it for use by decision makers, designers and facilities managers [11]. It is advisable to think ahead so that data collected as part of a sustainability assessment can be reported as Key Performance Indicators (KPIs) [24]. The use of (KPIs) and benchmarking is fundamental to any improvement strategy. An indicator system should provide a measure of current performance, a clear statement of what might be achieved in terms of future performance targets and a yardstick for measurement of progress along the way [12], [13].

It is as important standardize the methodology for calculating the KPI data and determine the resources needed to quantify, as the actual determination of KPI. In this step, it is appropriate to take into account the possibility of evaluating or consider the possibility of extracting data from information systems and their subsequent automated processing. Indicators must have targets to be based on strategies that are directly related to success factors and also features FM products that are relevant to the client organization. These objectives should be based on research rather than on arbitrary attributes. As a result, the life cycle of the FM requirements, critical success factors and goals change over time. Measurement system should be frequently reassessed and adapted to. The actual measurement methods should be designed to allow for changes to reflect developments and changes in strategy or core processes and measurement and continuous improvement of collection and reporting of data. Facility managers are familiar with measuring equipment, but each from a different perspective.

\subsection{Criteria for the Selection of Indicators}

During determine the consideration process of importance the measurement system and indicators are chosen in way that allows [14]: define the aims will be achieved; consider the extent to which a good result corresponds to the demand; identify the extent to which unmet needs and values of all parts of the client organization and provider organization; indicate the status of tasks, processes, operations or projects; compare; diagnosis; plan and monitor improvement measures; monitor change over time; identify factors that affect the performance; etc. 


\subsection{Required Characteristics of Indicators}

The selection process for choosing indicators must be easy to understand and the indicators must satisfy the following properties [14]: representativeness; adequacy of context; transparency; repeatability; clarity; grouping flexibility; criteria for their selection should be understandable and traceable; high data quality and knowledge of their uncertainties; sensitivity to changes over time; suitability for recording trends; suitability for comparison; sensitivity to interact with factors of success; relevance to the success factor; impact and controllability; data availability; possibility of updating; reasonable efforts for data collection; etc.

\section{Proposal of key performance indicators}

\subsection{Proposal of key performance indicators with impact on core business}

Based on much knowledge from studies to the operation of buildings respecting the criteria of sustainability the KPIs are divided in three groups: economic, social and environmental. For each group suggested KPI.

Economic indicators:

- Client satisfaction - with an performance;

- Customer satisfaction - with service;

- Profitability and gains during operation;

- Predictable costs (design, project, construction);

- Time predictability (design, project, construction);

- Productivity of employees;

- Faults, repair and replacement of small parts;

- Cleaning and maintenance;

- Costs associated with the operation and maintenance of buildings;

- Rents;

- The time of operation of the building;

- Wages of employees;

- Training of employees;

- Duties;

- Subsidies.

Social indicators:

- Qualifications of staff;

- Staff turnover (labour movement);

- Health and comfort, the sick absence;

- Safety/Protection;

- Hours of work;

- Satisfaction and skill;

- Equality and diversity;

- The performance of employees; 
- Accessibility (accessibility for people with special needs, employee access to networks of environmental engineering);

- Adaptability (ability to adapt to the individual needs of users, changes in user requirements, technological changes or changes of use);

- The burden on the environment (noise, emissions to the outside air, soil and water, glare and shield, shock and vibration, local wind conditions).

Environmental indicators:

- Environmental impact - during the operation of the building;

- Energy demand (in the design) - energy performance of building;

- Energy consumption in the construction process;

- Water demand (in the design) - water management of building;

- Water consumption in the construction process;

- Waste production - waste management of building;

- Production of waste in the construction process;

- Impact on biodiversity in the construction process;

- Transport from site of collection to the construction site for the construction process;

- The reconstruction of the environment;

- Taking into account the life cycle of buildings.

\subsection{Proposal of key performance indicators relating to facility management services}

To determine the KPI relating to FM services should from previous proposed KPI to allocate only those KPIs that are in accordance with the standard STN EN 15221-1 intended to support activities. Supporting the provision of basic activities of providers, thus facility management services, are yet associated with "space and infrastructure" as "people and organization" [4].

Economic indicators:

- Client satisfaction - with an performance;

- Customer satisfaction - with service;

- Faults, repair and replacement of small parts;

- Cleaning and maintenance;

- Costs associated with the operation and maintenance of buildings.

Social indicators:

- Qualifications of staff;

- Staff turnover (labour movement);

- Health and comfort, the sick absence;

- Safety/Protection;

- Satisfaction and skill;

- The performance of employees;

- Adaptability.

Environmental indicators:

- Environmental impact - during the operation of the building;

- Energy demand - energy performance of building; 
- Water demand (in the design) - water management of building;

- Waste production - waste management of building.

In Slovakia, thus proposed KPIs are currently not processed. Organizations and companies typically use their own tools and statistics. The most commonly used tool is the list (for example, customer satisfaction index, meeting quality objectives, internal processes, learning and growth, added value, internal audit, compliance plan, sales plan and compliance training, etc.).

\section{Determination of Weights Significance of Key Performance Indicators}

The overall performance score is obtained by a simple aggregation of all the points awarded for each criterion, all criteria are assumed to be of equal importance and there is no order of importance. This demands in-depth understanding of the environmental impact of a building. The relative importance of performance criteria is an important part of the decision if the stated objectives are to be achieved, for example, the public sector's opinion will definitely differ from that of the private developer. Therefore, the weighting of the criteria should be derived on a project-by-project basis and reflect the objective of a development [15].

There are several methods and approaches for determining significance weights. For example, the scoring method, the order method, method of paired comparisons of criteria - Fuller's method, the method of quantitative pair wise comparison of criteria, weights of the criteria in determining the geometric mean line, Saaty method, and the weights of criteria using tree objectives. The significance of various aspects of a proposed indicator was determined by a questionnaire completed by 30 respondents - professionals working in the field of facility management. Based on the results of the questionnaires were processed matrix on which to calculate the value of the weights and the significance of various aspects of the proposed subsequent KPI. To determine the importance weights are used multi-criteria method (multicriteria) decision-making that is based on mathematical modeling. Based on the study methods of multi-criteria analysis methods in question were confronted with the needs of the introduction of facility management and evaluation through key performance indicators in the organization. It is developed several options for determining significance weights. The first step is to determine the weight of the significance of economic, social and environmental aspects, and the second step is to determine the weights proposed KPI indicators. Determination of the weights of the two levels was carried out using multi-criteria analysis methods, and the geometric mean line method of paired comparisons - i.e. the Fuller's method and the Saaty method. To actually determine the importance weights appear to be the most suitable method of Saaty and geometric mean line. These methods use free program for multicriteria decision analysis MCA7 in determining the significance of weights aspects and KPI indicators [15]. The basis for the application of multi-criteria analysis has been previously mentioned questionnaire, completed a number of professionals working in the field of FM. There are the weights given to the significance of FM KPI with impact on core business of the organization and KPI relating to facility management services that are evaluated Fuller's method, Saaty method and the method of determining the weights of criteria geometric mean line in the table 1 and 2. 
Table 1: Scales significance aspects of facility management with impact on core business of the organization

\begin{tabular}{|c|c|c|c|}
\hline Aspects of FM & $\begin{array}{c}\text { Fuller's } \\
\text { method }\end{array}$ & $\begin{array}{c}\text { Saaty } \\
\text { method }\end{array}$ & $\begin{array}{c}\text { Geometric mean } \\
\text { value of line }\end{array}$ \\
\hline Economic aspect & 0,6364 & 0,5000 & 0,5000 \\
\hline Social aspect & 0,3333 & 0,3333 & 0,3333 \\
\hline Environmental aspect & 0,0303 & 0,1667 & 0,1667 \\
\hline
\end{tabular}

Table 2: Scales significance aspects of facility management services related to facility management

\begin{tabular}{|c|c|c|c|}
\hline Aspects of FM & $\begin{array}{c}\text { Fuller's } \\
\text { method }\end{array}$ & $\begin{array}{c}\text { Saaty } \\
\text { method }\end{array}$ & $\begin{array}{c}\text { Geometric mean } \\
\text { value of line }\end{array}$ \\
\hline Economic aspect & 0,6364 & 0,4182 & 0,4182 \\
\hline Social aspect & 0,1818 & 0,3162 & 0,3162 \\
\hline Environmental aspect & 0,1818 & 0,2656 & 0,2656 \\
\hline
\end{tabular}

\section{Evaluation}

There are the weights and the significance of aspects of the KPI with impact on core business of the organization in Tables 3, 4 and 5. The weights and the significance of aspects of the KPI relating to facility management services are in Tables 6, 7 and 8 . Scales significance indicators are determined by the percentage of the aspect of the importance weights.

Table 3: Weight significance of the economic aspect and KPI indicators with impact on core business of the organization

\begin{tabular}{|c|c|}
\hline Economic aspect & $\mathbf{5 0 \%}$ \\
\hline Client satisfaction - with a performance & 7,98 \\
\hline Customer satisfaction - with service & 5,23 \\
\hline Profitability and gains during operation & 3,18 \\
\hline Predictable costs (design, project, construction) & 3,18 \\
\hline Time predictability (design, project, construction) & 1,84 \\
\hline Productivity of employees & 5,23 \\
\hline Faults, repair and replacement of small parts & 1,84 \\
\hline Cleaning and maintenance & 1,84 \\
\hline Costs associated with the operation and maintenance of buildings & 7,98 \\
\hline Rents & 3,18 \\
\hline The time of operation of the building & 1,84 \\
\hline Wages of employees & 3,18 \\
\hline Training of employees & 0,47 \\
\hline Duties & 1,19 \\
\hline Subsidies & 1,84 \\
\hline
\end{tabular}


Table 4: Weight significance of the social aspect and KPI indicators with impact on core business of the organization

\begin{tabular}{|c|c|}
\hline Social aspect & $\mathbf{3 3 , 3 3 \%}$ \\
\hline Qualifications of staff & 6,18 \\
\hline Staff turnover (labour movement) & 0,59 \\
\hline Health and comfort, the sick absence & 0,91 \\
\hline Safety/Protection & 1,53 \\
\hline Hours of work & 1,59 \\
\hline Satisfaction and skill & 3,98 \\
\hline Equality and diversity & 0,57 \\
\hline The performance of employees & 7,9 \\
\hline Accessibility & 1,53 \\
\hline Adaptability & 5,83 \\
\hline The burden on the environment & 2,72 \\
\hline
\end{tabular}

Table 5: Weight significance of the environmental aspect and KPI indicators with impact on core business of the organization

\begin{tabular}{|c|c|}
\hline Environmental aspects & $\mathbf{1 6 , 6 7 \%}$ \\
\hline Environmental impact - during the operation of the building & 3,18 \\
\hline Energy demand (in the design) - energy performance of building & 4,37 \\
\hline Energy consumption in the construction process & 0,59 \\
\hline Water demand (in the design) - water management of building & 1,55 \\
\hline Water consumption in the construction process & 0,3 \\
\hline Waste production - waste management of building & 1,55 \\
\hline Production of waste in the construction process & 0,59 \\
\hline Impact on biodiversity in the process building & 0,96 \\
\hline Transport from site of collection to the construction site for the & \\
construction process & 0,3 \\
\hline The reconstruction of the environment & 0,96 \\
\hline Taking into account the life cycle of buildings & 2,32 \\
\hline
\end{tabular}

The highest weight of significance was assigned economic aspects (50\%). Respondents identified as the most important indicator of client satisfaction - with a performance $(7.98 \%)$. Conversely, the least important indicator appears training of employees $(0.47 \%)$. The social aspect of the significance of the weight gained (33.33\%). In this aspect of indicator the performance of employee has highest weight significance $(7.90 \%)$. As seems to be the least significant indicator have equality and diversity (0.57\%). Environmental aspects of the lowest weight gain significance $(16.67 \%)$. The following aspects of the greatest significance of the 
energy demand (in the design) - energy performance of building (4.37\%) and the least significant indicator appears water consumption in the construction process $(0.30 \%)$. The next will be necessary to consider whether the indicators, that appear to be least significant in terms of the allocation of weights significance in facility management in terms of the design and use of sustainable buildings, are excluded from consideration.

Table 6: Weight significance of the economic aspect and KPI indicators relating to facility management services

\begin{tabular}{|c|c|}
\hline Economic aspect & $\mathbf{4 1 , 8 2 \%}$ \\
\hline Client satisfaction - with a performance & 10,62 \\
\hline Customer satisfaction - with service & 7,95 \\
\hline Faults, repair and replacement of small parts & 7,16 \\
\hline Cleaning and maintenance & 6,44 \\
\hline Costs associated with the operation and maintenance of buildings & 9,65 \\
\hline
\end{tabular}

Table 7: Weight significance of the social aspect and KPI indicators relating to facility management services

\begin{tabular}{|c|c|}
\hline Social aspect & $\mathbf{3 1 , 6 2 \%}$ \\
\hline Qualifications of staff & 5,52 \\
\hline Staff turnover (labour movement) & 3,27 \\
\hline Health and comfort, the sick absence & 3,72 \\
\hline Safety/Protection & 3,95 \\
\hline Satisfaction and skill & 3,83 \\
\hline The performance of employees & 6,53 \\
\hline Adaptability & 4,80 \\
\hline
\end{tabular}

Table 8: Weight significance of the environmental aspect and KPI indicators relating to facility management services

\begin{tabular}{|c|c|}
\hline Environmental aspects & $\mathbf{2 6 , 5 6 \%}$ \\
\hline Environmental impact - during the operation of the building & 6,83 \\
\hline Energy demand - energy performance of building & 8,42 \\
\hline Water demand - water management of building & 6,08 \\
\hline Waste production - waste management of building & 5,23 \\
\hline
\end{tabular}

For indicators relating to facility management services was highest importance weight assigned to economic aspects (41.82\%). From these is as the most important indicator of customer satisfaction - with a performance (10.62\%). Less important is the indicator Cleaning and Maintenance $(6.44 \%)$. The social aspect of the significance of the weight gained $31.62 \%$. From this aspect indicator the performance of employees have highest weight of significance 
$6.53 \%$. As seems to be the least significant indicator have Staff turnover $(3.27 \%)$. Environmental aspects of weight gain significance $26.56 \%$. The following aspects have the greatest significance indicator Energy demand - energy performance of building $(8.42 \%)$ and less significant than it appears indicator Waste production - waste management of building $(5.23 \%)$.

When compared the proposed KPI impact on the core business with KPI relating to facility management services can be noted that the order of major groups is maintained, thus the greatest importance are economic indicators, followed by social and environmental indicators, finally, but in changing their importance weights.

\section{Conclusion}

For the both groups proposed KPI, the most important indicators are economic, social, and finally environmental indicators in terms of the hierarchy. With regard to the sustainability of buildings the most important and crucial are environmental indicators. From the perspective of professionals working in the field of FM, environmental indicators have reached the lowest weight of significance, but what causes that facility management is introduced mainly due to ever-increasing financial costs to building management and that is why it is most important aspect of economic and subsequently social. It should be noted, however, that the questionnaire was developed to assess the use of indicators in terms of sustainable buildings. The most effective environmental indicators have importance in terms of design, i.e. the design of buildings. Using the principles of environmental aspects - minimizing negative impact on the environment, energy efficiency in building design and construction, efficient use of water resources in building design and construction, to develop a detailed plan for waste management and measures to minimize emissions, minimize the negative impact on biodiversity, efficient solution in terms of material transport, destroying the environment and take into account the life cycle of buildings, it is possible to achieve higher energy efficiency, which ultimately contributes to the overall optimization of the total energy consumption in the usage phase of buildings. Investment to building sustainability through environmental indicators is a victory in terms of growth needed to stimulate sustainable buildings in the EU, while creating a sustainable and eco-friendly environment.

\section{Acknowledgements}

This paper was financially supported by the Slovak Grants VEGA No. 1/0405/13 and KEGA No. 004TUKE-4/2011.

\section{References}

[1] STN EN 15 221-4: (2012). Facility Management. Part 4: Taxonomy, Classification and Structures in Facility Management. Slovak Standards Institute.

[2] Larsson, N. (2011). SB Method and SBTool for 2011. Overview. International Initiative for a Sustainable Built Environment. October 2011.

[3] Straube, J. (2006). Building Science Digest 005. Green Building and Sustainability, October 2006. Building Science Press. 2006. 
[4] STN EN 15 221-1: (2007). Facility Management. Part 1: Terms and definitions. Slovak Standards Institute.

[5] Němcová, Z. (2009). Application of Key Performance Indicators in the Construction Industry: a comparison of the United Kingdom with the Czech Republic. 6 p.

[6] LAI, J. H. K., YIK, F. W. H. (2011). An analytical method to evaluate facility management services for residential buildings. Building and Environment 46 (2011) p. 165-175.

[7] Mc.DOUGALL, G., Kelly, J.R., Hinks, J., Bititci, U.S. (2002). A review of the leading performance measurement tools for assessing buildings. Journal of Facilities Management 2002; 1(2):142e53.

[8] Ling, F.H., Li, H.L., Yi, Y.L. (2008). A service quality measurement architecture for hot spring hotels in Taiwan. Tourism Management 29 (2008). p. 429-438.

[9] Ho, D.C.W. et. al. (2008). A survey of the health and safety conditions of apartment buildings in Hong Kong. Building and Environment 43 (2008). p. 764-775.

[10] Lai J.H.K., Yik F.W.H., Jones P. (2008) . Expenditure on Operation and maintenance service and rental income of commercial buildings. Facilities 2008; 26(5/6):242e65.

[11] Clements-Croome D.J., Wu S., John G. (2007). High-quality building services based on wholelife value. Reading: The University of Reading.

[12] British Council for Offices. (2007). Guide to post-occupancy evaluation. London: British Council for Offices.

[13] Jefferson I, Hunt D.V.L, Birchall C.A., Rogers C.D.F. (2007). Sustainability indicators for environmental geotechnics. Proceedings of the Institution of Civil Engineers. 160(ES2); p. 5778 .

[14] STN EN 15 221-3: (2012). Facility management. Part 3: Guidance on quality in Facility Management. Slovak Standards Institute.

[15] Krídlová Burdová, E., Vilčeková, S. (2013). Building environmental assessment system in Slovakia. Saarbrücken: LAP LAMBERT Academic Publishing. 2013. p. 114. ISBN 978-3-65931723-1.

[16] Korviny, P. (2003). Program pro multikriteriální rozhodovací analýzu. Ostrava 2003, 27 s. 